\title{
The Use of RFID Based Supply Chain Systems in Data Centers for the Improvement of the Performance of Financial Institutions
}

\author{
Noman A. Khan ${ }^{1} \&$ Raul Valverde ${ }^{2}$ \\ ${ }^{1}$ School of Management, Walden University, Minessota, USA \\ ${ }^{2}$ John Molson School of Business, Concordia University, Montreal, Canada \\ Correspondence: Raul Valverde, John Molson School of Business, Concordia University, Montreal, QC., H3G \\ 1M8, Canada. Tel: 1-514-848-2424 ext. 2968. E-mail: rvalverde@jmsb.concordia.ca
}

Received: October 24, 2013 Accepted: December 20, 2013 Online Published: February 13, 2014

doi:10.5539/emr.v3n1p24 URL: http://dx.doi.org/10.5539/emr.v3n1p24

\begin{abstract}
The advancement of RFID technology has been viewed by many as one of the most beneficial developments in the business world. Furthermore, the progress in this technology has motivated software and hardware manufacturers to leverage RFID capability and drive the adoption of RFID in the data center market. RFID technology holds promise in transforming supply chain management by providing real time intelligence for tracking enterprise assets. As it stands, the objective of RFID is to manage the entire life cycle of an asset by determining the time of initial asset acquisition, the asset's physical location, the asset's movement within a data center and the time of the asset's ultimate decommission. In addition, RFID is also capable of managing the motion of devices in and between data centers thus enhancing the ability to forecast data center capacity. Although data centers has been readily adopted and implemented in commercial sectors such as the retail environment, its introduction and implementation in the financial market sector has not occurred with similar speed and enthusiasm, suggesting presence of some reluctance. However, financial institutions are being under pressure from clients in order to provide real-time financial data and are looking at data centers integrated with RFID based supply chain systems for this purpose. The motivation for the present study arises from the growing body of literature which has examined the contribution of RFID supply chain systems in data centers and the motivation of financial institutions to use these data centers in order to become more competitive in the market. The paper asks the questions whether the RFID based supply chain systems in data centers can help to improve the performance of financial institutions.
\end{abstract}

Keywords: RFID, supply chain systems, data centers, supply chain management, supply chain finance

\section{Introduction}

There has been much discussion in the last couple of decades around the topic of Radio Frequency Identification (RFID) and supply chain systems. RFID can be best described as a system of identification in which an electronic device uses radio frequencies or magnetic field differences to communicate. Much of the original research and literature on the topic of RFID is focused on its use in the retail and production sectors of commercial enterprise. However, more recently the use of RFID technology has started to emerge in other areas in the corporate world. In particular, projects and proof of concepts are being conducted with the hope that RFID based supply chain systems will bring potential benefits in the management of supply chains within data center operations. For our purposes we define a data center as a "centralized repository" which can hold different types of equipments ranging from computers, servers, data storage devices, switches, routers, cabinets, racks, and technology related equipment. The function of a data center is to "store, manage, process and exchange" information entering and leaving the data center. Present day data centers are increasingly complex environments, making it imperative that C-level executives (Chief Information Officers, Chief Operating Officer, or Chief Executive Officer) responsible for these data centers possess a clear grasp of their business so that they can deliver consistent results.

This inevitably means there is a preeminent need to know assets on hand as well as their location. With the added pressure of market rules and regulations, companies are now required "to deliver improved compliance and business performance" (Eid \& Caldwell, 2007). This drive is shifting the allocation of IT budgets to compliance and corporate governance initiatives (Eid \& Caldwell, 2007). RFID's primary function is to provide proactive 
inventory management, and auditing. The mechanism is designed to enable IT organizations to align with regulatory requirements to ensure that they are able to provide accurate reports and minimize inventory discrepancies due to human error. RFID suppliers are in the process of enabling mass deployment of this technology to relevant customers.

As stated earlier, RFID technology is beginning to be adopted in a number of different industries, such as financial market data centers. Users of RFID technology view it as a technique for inventory management, efficient supply chain management, and improved security of data. In addition, RFID's stated objective has been to create checks and balances that foster better control of inventory management thereby creating higher value for the organization (Jones et al., 2005; Tan, 2007). This results in better visibility of asset inventory and ultimately affects the profit margin of a company.

Data Center executives need to have the ability to accurately track their assets from the time the assets arrive at the data center until the time the assets finally depart the facility. Executives are also interested in knowing if the asset moves during its stay at the data center. The use of RFID based supply chain systems is fairly new in the data center environment. As such, the early stage has a direct bearing on the adoption rate as financial market data center executives have serious concerns about security, particularly in regard to accessing the data center floor and wireless data transmission.

Recently, due to trends towards electronic trading in financial markets, financial institutions are under pressure to provide real time financial data for investors and are looking at data centers with integrated RFID supply chain systems as a possible solution to this challenge. In addition, data centers present an opportunity to improve other business areas such as asset management.

The central focus of this paper is to provide further understanding of how RFID supply chain systems in data centers can be used to improve the performance of financial institutions.

\section{Literature Review}

The early origins of radio frequency identification can be traced back to World War II when the Germans, Japanese, Americans, and British were utilizing radar to monitor aircraft activity. Following that RFID made its way to an early and primitive version, which was utilized in the 1950's at the US Department of Agriculture to study the movement of cows (Hodges \& McFarlane, 2004) for health purposes. As the technology matured; the versatile uses of RFID growed an interest in the commercial world. As a result, a considerable effort began to be expended on understanding the uses and applications of this new technology within the world of business.

Gartner Inc. forecasts that the RFID market is positioned to achieve worldwide revenues in excess of $\$ 1.2$ billion in 2008. This growth forecast is approximately $31 \%$ above what it was in 2007 (Gaudin, 2008). Even though this seems to be an aggressive forecast, RFID is rapidly gaining market share in the retail environment and more recently in data center operations. As noted by Gartner Inc. RFID is currently considered to be in the embryonic stage and is only being implemented in lab environments. Additionally, Gartner Inc. sites that RFID is considered an emerging technology with high growth potential which will create meaningful business benefits (Phillip Redman \& Woods, 2005).

As previously noted, the growth of RFID is increasing at a fairly brisk pace, there are systems being introduced everywhere, (Yoder, 2006) from classrooms, for educational purposes, public control programs, such as tolling, to corporate security usage. Therefore, it is not surprising that RFID is attracting the attention of academics and other observers. There has been an explosion in the literature relating to both the theory of RFID and the variety of applications available from both a commercial and social viewpoint. Some of this literature focuses on the uses of RFID as they relate specifically to the corporate world, particularly within financial markets and their data centers.

\subsection{RFID on the Retail Sector and Their Suppliers}

Many researchers have indicated that the retail sector has seen a proliferation in the use of RIFD technology (Attaran, 2007). In the retail environment RFID can perform numerous tasks, some of which include tagging products, controlling product shrinkage, assisting in streamlining and maintaining inventory by having a direct connection with the supplier. RFID can also assist in enhancing inventory accuracy, and reduction in out of stock inventory that can lead to consumers not purchasing an item, buying an item at another store, substitute for a different brand, or delay purchasing (Corsten \& Gruen, 2003; DeHoratius \& Raman, 2008). Rathore and Valverde (2011) proposed an RFID system for unattended stores that can help to automate checkouts without human intervention.

Today, RIFD technology used within the retail sector has the primary benefit of reduction in cost per unit to a 
fraction of a dollar. This is because unlike barcodes, RFID does not have to be product or item specific. Due to its product design and sizing RFID can be used over a wider range of operations. For example, a major retailer like Wal-mart can use RFID based supply chain systems to not only identify to the supplier up to date stock levels, but also provide ample information relating to consumer purchasing habits and needs. The general consensus around RFID, with its real time access to data, has led to retailers experiencing added value being created for their businesses (Auramo, Kauremaa, \& Tanskanen, 2005; Ranadive, 2006; Schuster, Allen, \& Brock, 2006). In actual fact (Auramo, Kauremaa, \& Tanskanen, 2005) has identified the following benefits to retailers (Table 1).

Table 1. Benefits of real time access to data

- Improvement to Customer Service

- Additional efficiency in productivity which allows employees to concentrate on other important business areas and operations

- Leads to increased speed of transfer within the supply chain network as well as the introduction of a greater level of flexibility

- Aids in planning and further development of new and existing products

- Provides strategic benefits and furthers competitive advantage

\subsection{RFID Based Supply Chain Systems}

Irrespective of whether an organization is product or service oriented, every business will have a supply chain, even if each organization may have a slight variability within said supply chain. The essence of managing the supply chain is to ensure that products move from their place of origination (the supplier) to the intended location (the store) in a prompt and efficient manner. One of the major benefits derived from RFID based supply chain systems is its ability to aid in transitioning a business toward the "real-time enterprise". "Real-time enterprise" can be best thought of as a 'business process' definition rather than a technology definition, although, technology is needed to create the "Real-time enterprise". The "real-time enterprise business model allows an organization to manage its operations in a predictable manner. In fact, CEO of Tibco Inc., Vivek Ranadive coined the term "Predicative Business" (Ranadive, 2006) to describe exactly this type of business model. A predictive business model requires access to real time information. RFID's role within such a context should be abundantly clear since it has the capability of allowing businesses to operate in an environment in which key supply chain information is transmitted in real time without any delays (Handfield \& Ernest L Nichols, 2002; Ranadive, 2006). Translating this process into the retail environment would mean a result where there are no delays on the the retailer's part in transmitting order requirements to the supplier because the information would be now communicated electronically from the retail store to the supplier. As a result, businesses at both ends of the supply chain can eliminate the need to produce and transmit any paperwork make for a more streamlined process.

As we can see, RFID implementation in the retail sector has yielded a positive impact, which can be observed in a number of areas. First, there is a noticeable improvement in customer service due to improved inventory tracking and faster order fulfillment. Second, there is a cost reduction advantage to the retailer resulting from a more efficient supply chain management. Third, as David Twist (Twist, 2005) has suggested, some analysts foresee that RFID could be instrumental in reducing the retailer and supplier need for warehousing space by up to $50 \%$ in the future. All of the aforementioned qualitative improvements and cost reductions will automatically increase the financial performance of the business, thereby the value returned to its owners and shareholders.

\subsection{RFID and Data Centers}

In an article published in 2007 Gartner Inc., noted that IT organization will be spending their budget dollars on initiatives that are aligned with Governance, Risk and Compliance. The compliance spending is being forced upon IT organization so that they can demonstrate conformity to relevant protocol that is likely to add business value for the company (Eid \& Caldwell, 2007).

This increase in spending has catapulted IT Asset Management into the spotlight. IT Asset Management also known in the market as ITAM is an IT business process discipline that focuses on improving cost and providing an accurate picture of what value IT brings to the organization. This value is to be measured by how IT 
organizations can establish visibility of the entire lifecycle of an asset.

Today's data centers have become much more complex and equipment dense due to Moore's Law of the ever shrinking computer chip and as they have shifted their focus on power management, cooling, virtualization, asset management, and data center efficiency. This implies that data centers can hold more equipment today than they did 30 years ago when we only saw larger mainframe units being utilized. If we look at the data center market trends, from 1980 to 2000, the IT market has been focused on such initiatives as IT Outsourcing and IT Centralization. Today data centers are in a transition phase; embracing initiatives which will improve service delivery, risk management, reduce complexity from business processes, establish Real-time Infrastructure and automation and most importantly understand the cost of resources being deployed.

This progressive change in the data center has warranted IT organizations to operate their data centers like a business. C-level executives are measured on reducing costs, delivery of high quality of service, and increasing transparency by exercising compliance requirements. Therefore, for IT to operate as a business with fiscal responsibility, the management team needs to consider such topics as IT budget management, cost center charge-backs to other business units on the use of IT assets and applications, regular IT audits on inventory and software to meet compliance requirements on Sarbanes-Oxley. In addition, they need to understand the financials of an asset, such as its purchase price; whether the asset is on maintenance, and when the asset will be decommissioned. Ultimately, this visibility enables C-level executives to be strategic about their business.

As noted in the previous chapter the drive towards creating a Real-time Enterprise has emerged to the forefront in the last several years. The big return "comes when the enterprise has developed predictive forecasting skills" so it is able to manage the business from a strategic view (Eid \& Caldwell, 2007). In the opening chapter of "Business@ The Speed of Thought" Bill Gates discusses how to address competition. He notes that companies must "do an outstanding job with information" (Gates, 1999). Additionally, he states "How you gather, manage, and use information will determine whether you win or loose" (Gates, 1999). It is important to note that Real-time Enterprise is not all about technology; it has more to do with driving initiatives that can remove unnecessary bottlenecks from business processes. IT Asset Management encourages that regular IT inventory and audits are completed to meet regulatory and financial requirements. In large, publicly traded companies IT managers are being asked to provide accurate and timely information to support the regulatory requirements of finance. This can support IT organizations in 1) conducting regular annual data center inventory; 2) completing a security audit; 3) providing depreciation costs for assets; 4) inventorying end of life assets; 5) inventorying end of lease assets.

IT organizations need to have agility to respond to these requests as they come up, especially in larger data centers where the rate of change is very high. There is a constant cycle of equipment being provisioned, installed, moved, redeployed and decommissioned. Conducting manual inventory and audits in large equipment dense data centers can make the effort costly and time consuming. Manual inventory does attempt to anticipate the rate of change in the data center; however, it does not provide a $100 \%$ account of the assets because by the time the inventory is completed, the collected information is out of date due to frequent or daily change management activities in the data center. Additionally, completing data center inventory and audits can become an expensive proposition due to the fact that data centers are ultra secure environments. It is not considered best practice to bring in an outside firm to conduct audits. Therefore, the individuals assigned to complete these inventories are highly paid IT individuals who have key roles within the data center but have been reassigned to low level tasks. Misdirecting high-end resources is largely inefficient as it undermines productivity and can reduce the profitability of the company.

The rapid expansion of the internet and the World Wide Web has had a significant impact on the number of computers as well as the volume of new data centers being built. These data centers are serving as repositories for the IT equipment and databases which many of the organization's employees may need to access on a regular basis. As discussed earlier, data centers today are faced with the issue of tracking information about their physical assets in the most cost effective and timely manner. To make matters more complicated data center operations presently have to incorporate Capacity Management in to their process. Capacity Management is one of the five disciplines identified in the Information Technology Infrastructure Library (ITIL) Service Delivery process. The Office of Government Commerce in the UK defines Capacity Management as the process which "ensures IT infrastructure is provided at the right time in the right volume at the right price" and most importantly IT is utilized in the most effective and efficient manner (ITIL-ITSM-WORLD.COM, 2001). There are five input variables that are used with the capacity management process as noted in (Table 2). 
Table 2. Input variable for capacity management (ITSMF-NL, 2005)

\begin{tabular}{|c|c|}
\hline Inputs & Definition \\
\hline Performance & - Analysis and fine tuning to deliver correct resource utilization \\
\hline Management & \\
\hline Workload & - Review and analysis of the business requirements on the type of workload \\
\hline Management & required and anticipated \\
\hline Application Sizing & $\begin{array}{l}\text { - Review if the required service levels can be sustained for today and tomorrows } \\
\text { needs }\end{array}$ \\
\hline Capacity Planning & $\begin{array}{l}\text { - Analysis of current and future use of IT infrastructure and the resources needed } \\
\text { to support the business }\end{array}$ \\
\hline Modeling & $\begin{array}{l}\text { - Simulations to review if the infrastructure will perform and review of "what if" } \\
\text { scenarios }\end{array}$ \\
\hline
\end{tabular}

To review Capacity Management from a real world scenario, data center managers would need to account for potential asset acquisitions based on business requirements such as new projects, new applications, possible data center expansions, consolidations activities and disaster recovery initiatives. Additionally, there are incidents such as data theft or misplacement, as well as the need for compliance on regulatory standards. This brings us to the question of what are C-level executives doing about IT Asset Management? Certainly as discussed earlier IT spending is being devoted to find multiple technologies and business processes to address the emergence of a Real-time Enterprise. RFID by itself can only do so much to enable a predictive business because it is only one piece of the asset management technology. The RFID microchip can store about 2 kilobytes of data; this can include a unique ID for the asset and other asset information. Coupled with IT Asset Management software a powerful business application can be formed. Software and Hardware vendors like Cisco, HP, and IBM, are doing exactly this, by leveraging RFID and creating and marketing Asset Management processes and software solutions. Table 3 below provides the focus areas of these vendors.

Table 3. RFID supply chain system solutions by vendor

\begin{tabular}{|c|c|c|}
\hline Vendor & Market Message & Market Presence \\
\hline Cisco & $\begin{array}{l}\text { Automatic Up-to-Date } \\
\text { Equipment Tracking }\end{array}$ & Early Development \\
\hline HP & $\begin{array}{lcr}\text { Reduce } & \text { property } & \text { loss, } \\
\text { increase } & \text { security } & \text { and } \\
\text { improve } & \text { on } & \text { audit } \\
\text { control } & & \end{array}$ & $\begin{array}{l}\text { Early Development, } \\
\text { however significant } \\
\text { progress has been } \\
\text { made } \\
\text { customers }\end{array}$ \\
\hline
\end{tabular}

$\begin{array}{llrl}\text { IBM } & \text { Fulfill IT asset } & \text { Well into } \\ \text { inventory reporting, } & \text { developing an RFID } \\ \text { auditing and regulatory } & \text { solution. } \\ & \text { compliance } \\ & \text { requirements while } \\ & \text { reducing IT asset } \\ & \text { management costs }\end{array}$

Solution Description

- Developing a hardware and software solution which will utilize RFID, and Cisco's Wireless LAN solutions. The solution "detects equipment with active RFID tags, then sends the equipment location data to an internally-developed asset-tracking application" (Cisco, 2008)

- Developed the HP Factory Express RFID Service for Data Centers. The solution tracks all critical data center assets throughout its lifecycle. The service "automates and tracks device movement" while providing accurate inventory data (HP.com, 2008).

- Developed the Asset Tracking and Visibility (ATV) using RFID technology by utilizing software, services and hardware. It uses IBM's Websphere ${ }^{\circledR}$, IBM DB2 ${ }^{\circledR}$ and IBM Tivoli ${ }^{\circledR}$ products (IBM.com, 2008).

As noted in Table 3, software and hardware vendors like Cisco, HP and IBM are developing sophisticated and effective asset tracking systems for the data center market, while aligning their solutions to IT Asset Management initiatives. David Wyld (Wyld, 2006) discussed in his paper RFID 101: the next big thing got 
management that data center assets hold an extensive amount of information, therefore there is a need for data centers to employ robust systems that will assist with the process of data control and monitoring (Wyld, 2006).

\subsection{The RFID vision for the Data Center}

Frank Lanza worldwide director of the HP RFID Program states; "Physical inventory of IT assets is critical in data centers, especially those with thousands of devices" (HP.com, 2006). Lanza has also pointed out that the "HP RFID technology could enable better accuracy of inventory, increase security and reduce data center operational and auditing costs." (HP.com, 2006). HP utilizes RFID readers and RFID tags to monitor the location of all data center assets. The technology is able to determine when a new device is added, and when a device is moved. HP is able to provide a dashboard for data center managers so they can plan and manage their infrastructure. As noted in Table 3 Cisco, HP and IBM are starting to develop RFID solutions for the data center which promise to address the high costs of IT Asset Management. The vision is in its infancy and at the present time not much has been written on the topic of using RFID in a data center as compared to supply chain, warehouse management and the retail market.

Data Centers in financial markets hold a great deal of information that is related to their customers. RFID based supply chain systems become attractive on the basis that they can provide additional security. As well, from an IT Asset Management perspective RIFD systems can provide a solution where a complete asset inventory can be conducted in a matter of minutes rather than hours, days or even weeks (Kenney, 2008). This ability is an important ingredient in ensuring that data center managers can comply with current legislations and regulations. IBM has also been working very closely with RFID for the purpose of inventory management and auditing of data center assets. They have outlined the following benefits below, which can be derived from the use of RFID for data centers:

- Simplify tracking of physical IT assets which includes inventory and auditing

- Assist in meeting the requirement for IT asset-related reporting for legal and regulatory policies.

- Reduce the potential for errors related to asset information

- $\quad$ Easy integration with existing barcode and text-based tracking systems

- Time savings in locating, inventory and audit of IT assets, which ultimately improves the productivity of IT Staff

Some of the literature available on RFID for data centers at financial institutions and corporations indicates that security is a barrier in moving forward. The primary concern around security is the possibility that potential intruders could browse the airwaves, similar to finding a WiFi-Hotspot, and attack the RFID system (Wang, Cheung \& Liu, 2006). It is obvious that in order to ensure that RFID is going to be embraced by data centers, the RFID based supply chain systems have to comply with the standards and levels of security to meet compliance and regulations requirements (Rees, 2004).

\section{Research Methods}

The collection of primary data is carried out with the aid of a survey and direct face - to - face interviews. The intention being that the combination of the two methods would add depth and value to the findings (White, 2000). Interviews were conducted with individuals who have direct responsibility for driving the decision and the implementation of IT Asset Management initiatives.

Twelve questions were chosen for the final survey, which comprised of the open and close method as well as multiple choices. The survey was designed to capture responses such as department and position, as well as questions on the use of RFID in data centers within the interviewees' organization. Space was also provided to allow the respondents to make additional comments where they deemed appropriate. By working closely with the representative of the organization, the response rate on the survey was much higher than expected with a total of 51 out of 80 responses or 63.75 percent. The survey was submitted electronically once the survey candidates were identified. The selection process was completed by working with the manager of the organization and was distributed to members identified by the manager. The following financial organizations were targeted,

- Citigroup

- Bank of America

- Barclays Capital (New York)

- JP Morgan and Chase

- MBNA 
- Lloyds Bank

- Banco Santander

To support and enhance the findings of the survey, two interviews were conducted with senior level executives of Citigroup and Reuters who have direct responsibility on managing the day-to-day operations of a data center and drive process improvements on the IT Asset Management front. These individuals were chosen because they are currently in the process of launching ITAM initiative within their organizations. Due to the sensitive nature of these interviews, permission was not granted to publish the name of the individuals at these institutions in order to protect their privacy. Both interviews were conducted during a face to face meeting in New Jersey, United States.

As the research and data collection progressed, the data was collated, studied, and evaluated to assess if the collected information was relevant and accurate. The survey and the interview questions were developed in accordance with the collected data to gain additional insight into the subject. The next stage of the research was to make arrangements for the survey and interviews. The survey questions were submitted to the relevant organizations by the method described in Appendix A. As noted previously, the two interviews were conducted on location at the interviewee organization.

Once the survey and interviews were completed, it was incorporated into the research paper. However, with any research of this nature, additional data and topics were identified that required further re-edits. Once the paper could be considered a first complete draft, it was again checked for thoroughness for its content and if it had addressed the objectives of the study. Additionally, the presentation and accuracy was reviewed before the paper was finalized for presentation.

\section{Results and Analysis}

The survey was submitted to financial organizations from both the US and UK due to the nature of global markets. This was undertaken to ascertain whether there existed perceivable differences of opinion regarding the topic of ITAM and RFID in data centers.

As noted in Table 4, the aim of the survey was to have a cross-section of personnel to respond. Majority of the people who responded to the survey were from a management level. However, it should be noted that where the table indicates senior management it does not necessarily mean that the individuals were employed at senior levels; that only occurred in one case.

Table 4. Positions of respondents

\begin{tabular}{lll}
\hline What position do you hold in the organization you work for & US & UK \\
\hline Senior Management & 11 & 12 \\
Management & 8 & 5 \\
Data entry & 6 & 1 \\
IT department & 4 & 2 \\
Other & 2 & 0 \\
\hline
\end{tabular}

It should be noted that all of the following graphical illustrations in this section of the chapter have been denoted by the following identifiers

$1=$ US Respondents

$2=$ UK Respondents

In addition, to enable a fair level of comparison, the results from the completed survey have been converted into percentage terms rather than the simple numerical response. Questions 4 and 5 (Figure 6 and 7) were intended to ascertain where RFID based supply chain systems in data centers are being considered to have the most impact within the corporate management system. The responses confirmed that the market message today on RFID is tied back to IT Asset Management initiatives. Both the US and UK respondents embraced and understood the real-time enterprise message. Both respondents also showed a genuine interest in improving service levels within their IT organization to satisfy their internal customers. This was interesting to note as it suggests there is some concern in the IT arena about their ability to deliver quality services. It was also not too surprising to see that the UK scored slightly higher on considering RFID based supply chain systems based on IT Governance requirement than the US. This difference is notable because UK organizations rely on driving their data centers based on strict standards and requirements. Even though the US scored lower, the difference should not be 
interpreted as the US not grasping the importance of IT Governance. If we look at IT Governance drivers, they are all based on the root of driving IT Asset Management initiatives. (Figure 1) paints a similar picture and re-validates that RFID is indeed aligning itself to improve IT Operations. Both US and UK respondents appreciate that RFID will bring value to their ITAM initiatives and provide regulatory control.

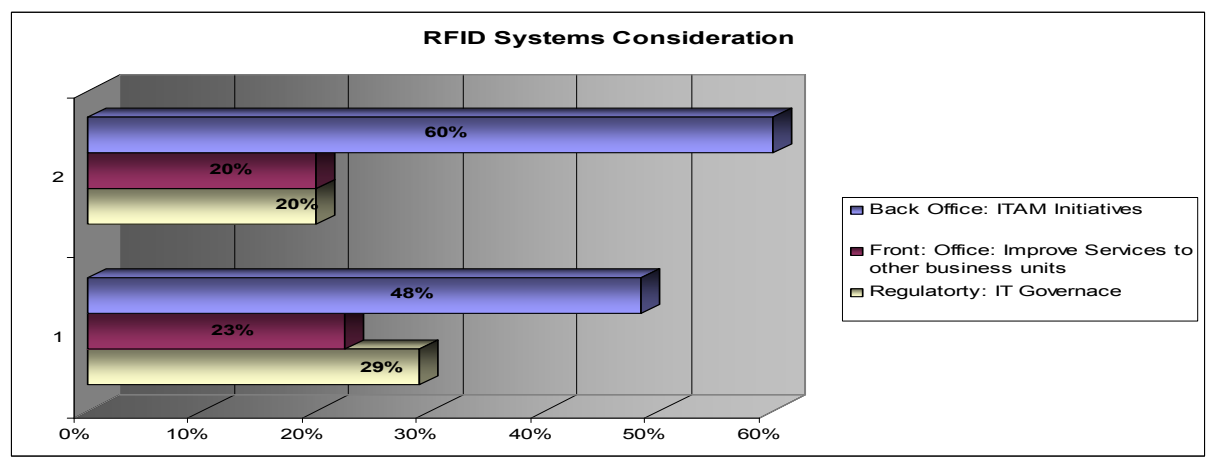

Figure 1. Question 4 - RFID based supply chain systems in data centers consideration

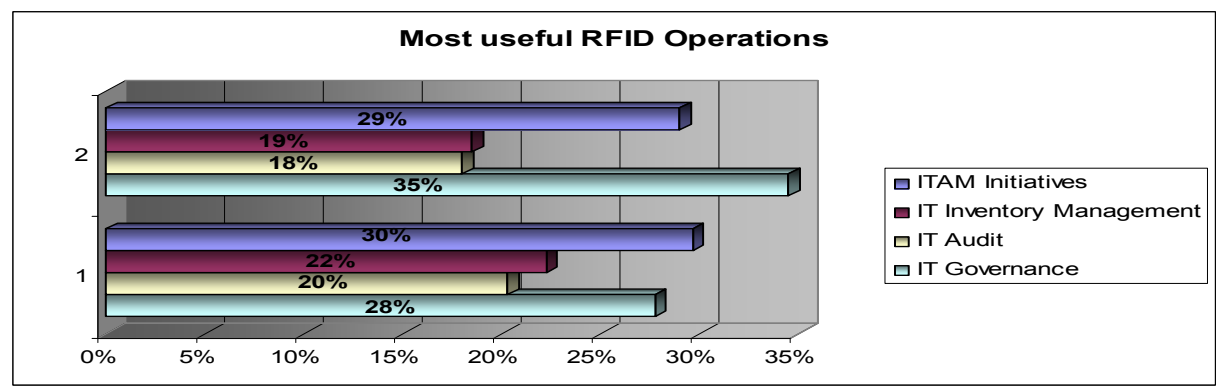

Figure 2. Question 5 - Most useful RFID Operations

The US and UK responses on question 6 (Figure 3) were similar in their scores. Both the US and UK scored higher on the purpose of RFID. The implementation of RFID is meant to address the assets within the data center It was interesting to see that the respondents also saw an application for RFID based supply chain systems outside the four walls of the data center. While this response does not provide too much value to the research it does point out that organizations are considering asset management solutions outside the confines of the data center. Additionally, both the US and UK organizations envisioned RFID being used throughout the company as well as warehouses where assets might be sitting in storage or transit.

Question 7 (Figure 4) focused on the Benefits of RFID in the data center environment. The US and UK responses to question 7 were similar in their scores. The similarity in the responses reinforces the idea that these organizations are global and tend to adapt to market imperatives. As noted in (Figure 5) both the US and UK see RFID bringing much greater value to the IT Lifecycle. IT asset re-deployment also seems to be an area of concern; an issue that was also highlighted in the interviews at Citigroup and Thomson Reuters.

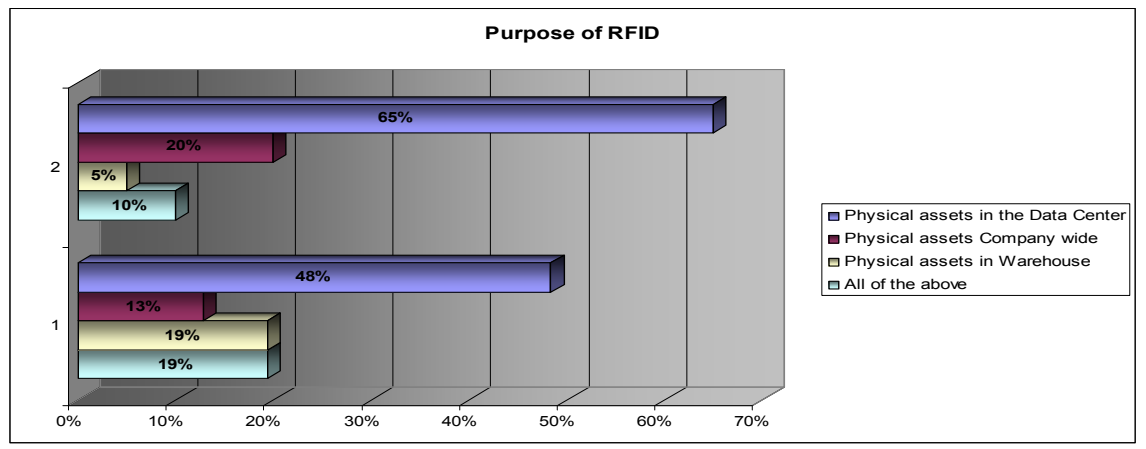

Figure 3. Question 6 - Purpose of RFID 


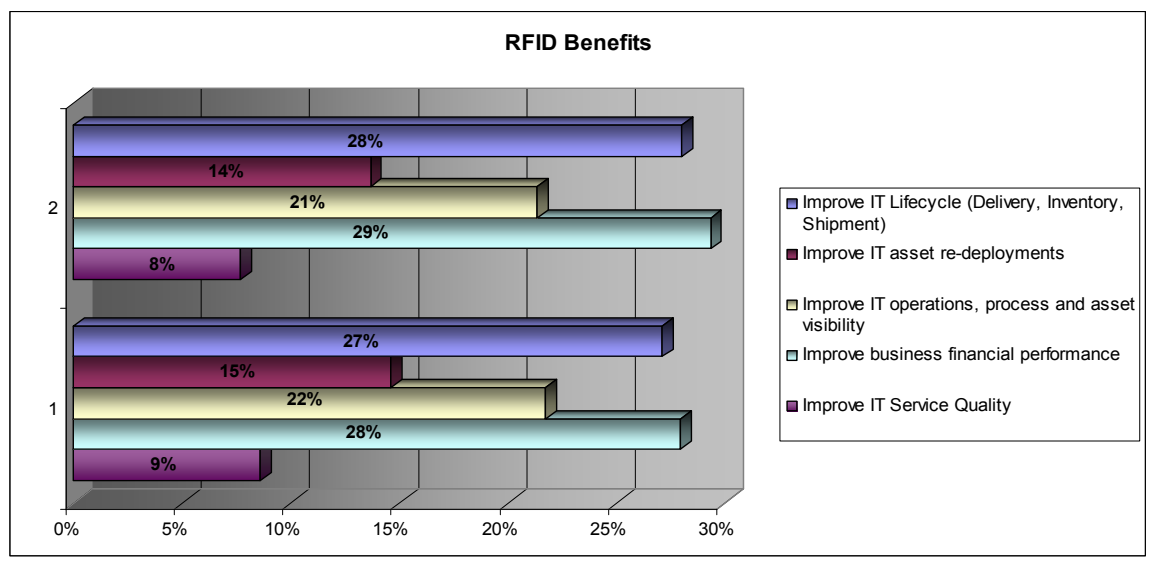

Figure 4. Question 7 - RFID Benefits

Based on this question relating to RFID and its impact on risk, it was expected that the UK respondents consider the implementation of RFID in data centers would potentially increase the areas of risk within financial institution. This concern lies predominantly in the area of data protection and privacy (see Figures 5, 6, and 7) One UK respondent made the comment that anything new in technology comes with an inherent risk and the last thing that her bank could afford at this stage was additional risk. The US provided a more positive opinion. A US manager mentioned that RFID should be viewed as an opportunity rather than a threat. Furthermore, the opportunity should be used to reduce problems area within the enterprise.

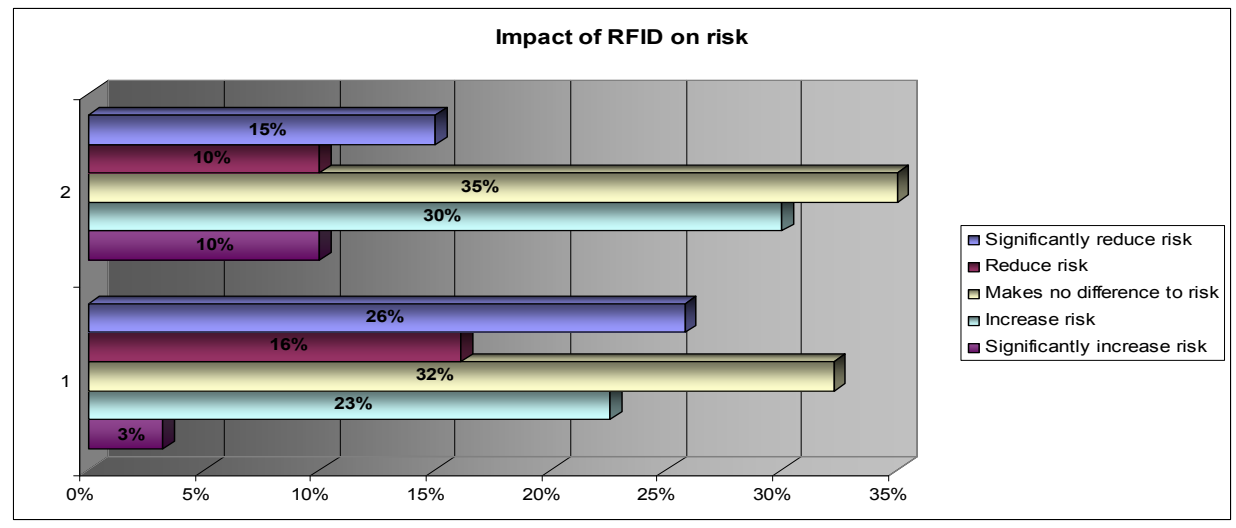

Figure 5. Question 10 - Impact of RFID on risk

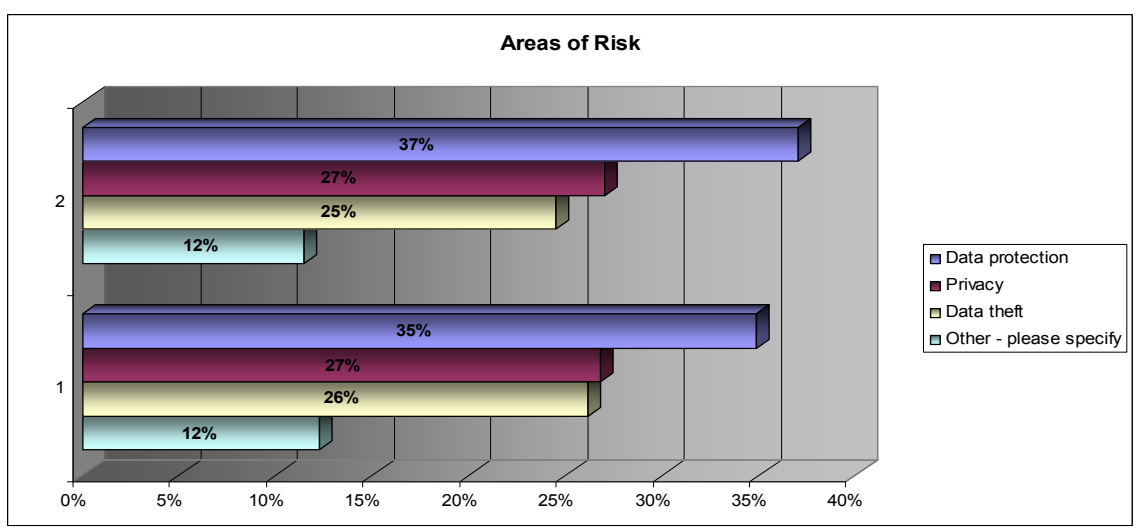

Figure 6. Question 11 - Impact of RFID on risk 


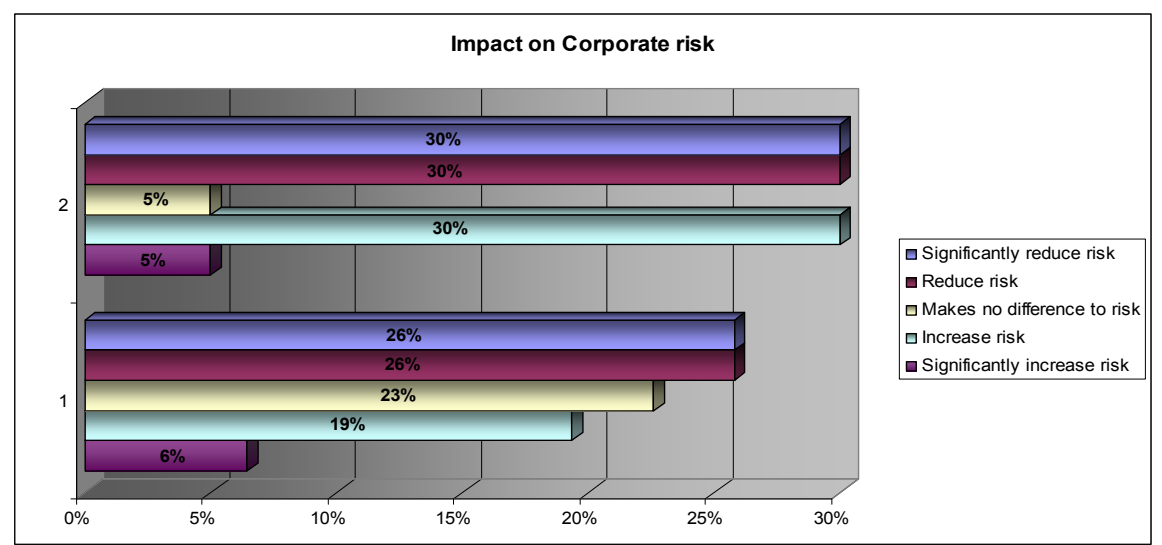

Figure 7. Question 12 - Impact on Corporate risk

In support of the survey and to add value to this research it was important to complete two interviews which were conducted in person. Both participants were at a Senior Vice President level responsible for running the day to day operations of multiple data centers globally. Both individuals reported into Executive and Managing Director level managers. Permission was sought to record the interviews so that they could be presented as part of this study to meet the dissertation requirements and to have them printed for later consumption. The questions presented during the interviews were slightly different as the interview was also designed to glean information on tired to seek financial and return on investment information. The questions are located in Appendix A. Both of the interviews re-validated the current understanding of RFID in the data center market.

The roles of the interviewees are geared towards the operational side of data center operations. These roles are considered pivotal for the organization because they drive key initiatives behind the IT Asset Management principles, which are to focus the IT organization in managing the physical, financial and contractual aspects of IT assets, as well as to address and implement process changes.

Both Interviewee 1 and Interviewee 2 displayed reasonable understanding of RFID. However, interviewee 1 had more of a business management background while interviewee 2 held a computer science degree as well as an engineering degree.

On the issue of using RFID based supply chain systems in data centers as a solution for their business needs, both respondents seem to immediately focus on visibility for their assets. Interviewee 1 offered more on the business process overview gaps and why it is important to implement a process which can assist them in managing the life cycle of IT assets. Interviewee 2 focused on inventory and audits needs of the organization, and pointed out the disappointments with investments made so far to address the inventory and audit needs.

Regarding RFID based supply chain system benefits; interviewee 1 highlighted an important area that IT organizations tend to typically struggle with. When a company is looking to re-deploy assets it is looking to increase profitability. Redeploying an existing server for another purpose is an example where the company is managing available resources to maintain lower operating costs. Interviewee 2 also seemed to place value on the benefits and understood that RFID would enable the IT organization to accurately charge back, which indicates that the implementation of RFID will increase operational efficiency and improve cost.

On the question of RFID based supply chain systems improving operating costs, interviewee 2 was unable to release too much information but did state that the organization can spend up to $\$ 10,000$ for inventory of their data centers. Interviewee 1's organization had been able to generate significant savings by repurposing and redeploying their IT assets.

Concerning the question of RFID based supply chain systems improving inventory and audits it should be pointed out that with an RFID enabled data center, there is still a human factor involved in conducting an inventory audit; however, the process is much simpler and easier. The audit is completed by opening the rack or cabinet and rolling a mobile cart which is equipped with an RFID reader. The RFID reader is able to read, inventory and audit all of the devices in the rack within 15 minutes or less.

On the topic of RFID based supply chain systems' potential to deter asset shrinkage, both interviewees viewed asset shrinkage as an issue and thought that RFID would be able to address the problem with relative ease. Neither interviewee was able to share cost information on the issue of asset shrinkage. 
On the subject of RFID based supply chain systems improving charge backs, interviewee 1 discovered that they were not accurately charging back and leaving money on the table. Interviewee 2 perceived the value; however was not able to provide tangible information on the topic. While charge backs are internal budget transfers between departments, they are still important business metrics to measure the IT organization.

\section{Conclusions}

Will RFID based supply systems in data centers improve the performance of financial institutions? RFID is a powerful technology that can offer organizations increased visibility for greater operational efficiency. As highlighted in the surveys and the interviews, RFID is only a hardware solution; it relies on supply chain software like HP Asset Center to enable the visibility and process management to invoke the operational efficiencies.

This survey provided broad views on how RFID based supply chain systems are being deployed within organizations. Both the US and UK respondents from financial institutions held a positive outlook on the potential benefits of RFID based supply chain systems in data centers. Additionally, based on the responses, the US respondents seemed to have a more positive opinion of RFID based supply chain systems, as they anticipated RFID technology creating value to the entire business rather than just being used as a preventive option. The research revealed that the UK respondents believed that the implementation of RFID would potentially increase the areas of risk within financial institutions.

The interviews on the other hand were able to focus more on the current state of the two organizations and understand the implied benefits achieved with the implementation of RFID based supply chain systems in data centers. Additionally, the two interviews conducted highlighted that the potential benefits of RFID based supply chain systems seem to resonate with these institutions. Both of these institutions were moving forward with the implementation of RFID in data centers as they realized that it would assist in driving their IT Asset Management projects and bringing them closer to becoming an organization that creates and provides bottom line value to their company.

This recognition was apparent during the review of the survey and the interviews. Several key messages were revealed during the survey and question process. First, the data center executives perceive much value in the use of RFID based supply chain systems to manage and implement their IT Asset Management initiatives. Second, they also comprehend that RFID based supply chain systems can significantly impact their operational cost and strategically position them as an organization that provides business value.

With an RFID enabled data center, there is still a human factor in conducting an inventory audit; however, the process is much simpler and easier. RFID based supply chain systems also deter asset shrinkage and improve charge backs.

As noted previously, RFID based supply chain systems are at an early stage of development in the sphere of data center operations for IT asset tracking. The market is positioned to evolve further in the next 5 to 10 years where additional RFID hardware and software vendors are going to make their way into the market as leaders. There will be a need to re-visit the data center market to gain a deeper understanding of how RFID technology coupled with a supply chain software solution will improve the financial performance of an organization. The areas to focus on will be; 1 ) whether RFID based supply chain systems promote accurate financial statement for fixed assets? 2) Will RFID update all systems when there is an event in the asset life cycle; 3) will RFID reduce asset shrinkage and data security?

\section{References}

Attaran, M. (2007). RFID: an enabler of supply chain operations. Supply Chain Management: An International Journal, 12(4), 249-257. http://dx.doi.org/10.1108/13598540710759763

Auramo, J., Kauremaa, J., \& Tanskanen, K. (2005). Benefits of IT in supply chain management: an explorative study of progressive companies. International Journal of Physical Distribution \& Logistics Management, 35(2), 82-100. http://dx.doi.org/10.1108/09600030510590282

Cisco. (2008). Cisco Tracks Data Center Equipment with RFID and Wireless LAN So-lutions. Retrieved July 20, 2008, from http://www.cisco.com/web/about/ciscoitatwork/highlights/092820071.html

Corsten, D., \& Gruen, T. (2003). Desperately seeking shelf availability: an examination of the extent, the causes, and the efforts to address retail out-of-stocks. International Journal of Retail \& Distribution Management, 31(12), 605-617. http://dx.doi.org/10.1108/09590550310507731

DeHoratius, N., \& Raman, A. (2008). Inventory record inaccuracy: an empirical analysis. Management Science, 
54(4), 627-641. http://dx.doi.org/10.1287/mnsc.1070.0789

Eid, T., \& Caldwell, F. (2007). Audits and Events Drive Governance, Risk and Compliance Spending. Retrieved July 20, 2007, from http://www.gartner.com/resources/145900/145903/audits_and_events_drive_gove_145903.pdf

Gates, W. H. (1999). Business @ The Speed Of Thought. New York: Warner Books, Inc.

Gaudin, S. (2008). Gartner: Global RFID market to top $\$ 1.2 B$ this year. Retrieved May 21, 2008, from $\mathrm{http}: / / \mathrm{www}$. computerworld.com/action/article.do? command=viewArticleBasic\&articleId=9064578

Handfield, R. R., Ernest L., \& Nichols, J. (2002) Supply Chain Redesign - Transform-ing Chains into Integrated Value Systems. Upper Saddle River. NJ: Finan-cial Times Prentice Hall.

Hodges, S., \& McFarlane, D. (2004). RFID: The Concept and the Impact. The Security Economy (p. 59). France: OECD Publications.

HP.com. (2006). HP Creates RFID Technology for Tracking Data Center Assets. Retrieved May 31, 2008, from http://www.hp.com/hpinfo/newsroom/press/2006/061017b.html

HP.com. (2008). HP Launches RFID Service for Tracking Data Center Assets. Retrieved July 20, 2008, from http://www.hp.com/hpinfo/newsroom/press/2008/080609a.html

ITIL-ITSM-WORLD.COM. (2001). Capacity Management. Retrieved July 18， 2008， from http://www.itil-itsm-world.com/itil-7.htm

ITSMF-NL. (2005). Foundations of IT Service Management, based on ITIL(R). Zaltbommel, Netherlands: Van Haren Publishing.

Jones, P., Clarke-Hill, C., Hillier, D., \& Comfort, D. (2005). The benefits, challenges and impacts of radio frequency identification technology (RFID) for retailers in the UK. Marketing Intelligence \& Planning, 23(4), 395-402. http://dx.doi.org/10.1108/02634500510603492

Kenney, B. (2008). RFID for the Datacenter. Retrieved March 28, 2008, from http://www.industryweek.com/ReadArticle.aspx?ArticleID=15746

Ranadive, V. (2006). Chapter 1: Why Predictive Business Today? The Power to Predict. New York: McGraw-Hill, p. 1.

Rathore, A., \& Valverde, R. (2011). An RFID based E-commerce solution for the implementation of secure unattended stores. Journal of Emerging Trends in Computing and Information Sciences, 2(8), 376-389.

Tan, L. (2007) Bank taps RFID in data center. Retrieved April 20, 2008, from http://www.zdnetasia.com/news/business/0,39044229,62032978,00.htm

Twist, D. C. (2005). The impact of radio frequency identification on supply chain facilities. Journal of Facilities Management, 3(3), 226-239. http://dx.doi.org/10.1108/14725960510808491

Wang, Y., Cheung, Y. M., \& Liu, H. (2006). Computational Intelligence and Security (pp. 778-780). New York: Springer Berlin Heidelberg.

White, B. (2000). Dissertation Skills for Business and Management Students. United States: Thomson.

Willis, Nahoko Mitsuyama. (2005). Hype Cycle for Wireless Networking Infrastructure, 2005. Retrieved from http://www.gartner.com/resources/127800/127884/hype_cycle_for_.pdf

Wyld, D. C. (2006). RFID 101: the next big thing for management. Management Research News, 29(4), 154-173. http://dx.doi.org/10.1108/01409170610665022

Yoder, R. C. (2006). Using RFID in the classroom to teach information systems principles. Journal of Computing Sciences in Colleges, 21(6), 123-129.

\section{Appendices}

\section{Appendix A: Interview Questions}

1. What is your current role in the organization you work for?

2. What level of experience do you have with RFID technology?

3. Why has the institution considered an RFID solution? 
4. What are you using RFID for?

5. What are the benefits that you are hoping to reap from using RFID for the bank?

6. Has the use of RFID improved operating costs?

7. Will you continue to invest in RFID?

8. Has RFID improved your ability to complete inventory and inventory audits?

9. Has RFID impacted asset shrinkage?

10. Has RFID impacted the banks ability to manage asset charge backs to other business units?

\section{Appendix B: Interview Transcripts}

\section{Interviewee 1 Transcripts}

Important Notes

Thank you for agreeing to take part in this interview.

This interview is being carried out as a part of an educational research project required for a university course.

The questions included will be reviewed at the meeting. They have been provided for reference.

Please note:

The interview is being carried out on a confidential basis. No personal information is being asked for, nor will any information be divulged that could identify the organization without the express written permission of the organization

1. What is your current role in the organization you work for?

2. What level of experience do you have with RFID technology?

3. Why has the institution considered an RFID solution?

4. What are you using RFID for?

5. What are the benefits that you are hoping to reap from using RFID for the bank?

6. Has the use of RFID improved operating costs?

7. Will you continue to invest in RFID?

8. Has RFID improvement your ability to complete inventory and inventory audits?

9. Has RFID impacted asset shrinkage?

10. Has RFID impacted the banks ability to manage asset charge backs to other business units? 


\section{Appendix C: Survey Questions}

\section{SURVEY: RFID in the Data Center}

1. Default Section

IMPORTANT NOTES

Thank you for agreeing to take part in this survey.

This survey is being carried out as a part of an educational research project required for a university course.

The questions included are of a simple or multiple-choice nature. In terms of the former we would ask you to tick the appropriate selection, and in the later, to indicate your choices based upon the criteria that are indicated.

Where relevant, space has been provided at the end of the questionnaire to allow for in-dividual comment should you consider this appropriate. Please feel free to use this option using the separate sheet at the end of the questionnaire. Thank you.

Please note:

The survey is being carried out on a confidential basis. No personal information is being asked for, nor will any information be divulged that could identify the organization without the express written permission of the employer

\section{Name of your Institution?}

\section{Where is your office located?}

us

UK

3. What position do you hold in the organization you work for
Senior management
Management
Data entry
Ir department
other

4. How long have you worked for the organization
Longer than five years
Two to five years
Less than five years

5. What is the level of your experience in RFID (Radio Frequency Identification processes)?

Have experience with the systems and operations

Understand concept have limited experience

I understand the concept 


\section{SURYEY: RFID in the Data Center}

6. If your organization already has or is considering the introduction of RFID systems, which of the following areas of the business is or will this implementation take place

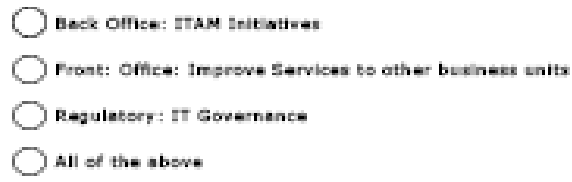

7. In your opinion and on a scale of $1-4$, ( 4 being most beneficial)in which of the above areas will RFID prove most useful?

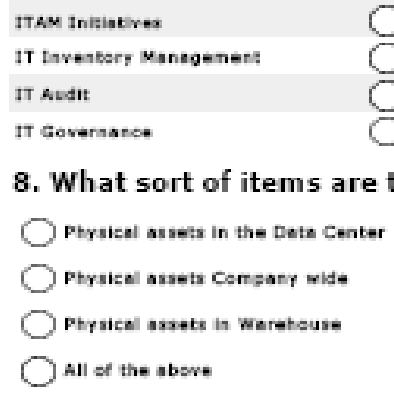
Ptrsical assets in the Deta Center
Ptysicel assets Company wide
Physical assets in warehouse
All of the absere

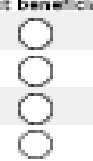
benetecial

8. What sort of items are the RFID systems being incorporated into?

9. On a scale of 1 to 5 ( 5 being most beneficial), what do you think are the main intended benefits for the introduction of RFID systems into your organizations?

Imsreve It Ufecycle

not benefieial least benefieial

(Delivery, innentery,

saipment)

Improve IT asset re.

depleymerts

Improve IT eperetisns.

viebit:

Improve busiress

finarcial pertermarce

Improve IT Service

Quality

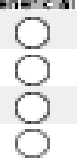
reasorabiy beneticial

being nast beneficial
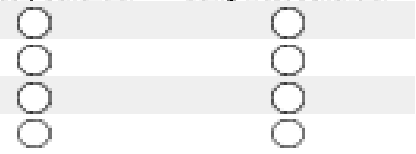


\section{SURVEY: RFID in the Data Center}

10. On a scale of 1 to 4 ( 4 being where the most barriers), what do you think are the main barriers for the introduction of RFID systems into your organizations?
to change
Lacks senior
make decision
$\bigcirc$ cisco
$\bigcirc \mathrm{HP}^{\circ}$
$\bigcirc \mathrm{IBM}$
$\bigcirc$ sun
other

Organizational resistance

no barriers

less barriers

0

Unproven business value

management support

Need more information to

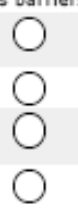

some barriers

most barriers

11. Who are your Primary IT Service Management Vendors

12. When considering the RFID systems, what is your opinion in terms of the impact that they will have upon risk within the organization?
significantly reduce risk
Reduce risk
Makes no difference to risk
Increase risk
significantly increase risk

13. On a scale of 1 to 4 ( 4 being greatest risk), in terms of company data, where do you think the greatest element of risk is?

Data protection
Privacy
Other - please specify




\section{SURVEY: RFID in the Data Center}

14. What impact do you think the introduction of RFID systems will have on the level of corporate risk in these areas?

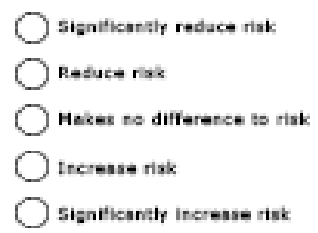

15. Please use this space to add additional information and comment on the topic of RFID within Data Centers.

$=1$
$\nabla$

\section{Copyrights}

Copyright for this article is retained by the author(s), with first publication rights granted to the journal.

This is an open-access article distributed under the terms and conditions of the Creative Commons Attribution license (http://creativecommons.org/licenses/by/3.0/). 